\title{
ANTIHISTAMINES IN OPHTHALMOLOGY*
}

BY

\section{LEWIS NÉMETH}

Histamine plays an important rôle in the mechanism of allergy or hypersensitive diseases of the constitution. This substance is to be found preformed as histidin in the cells; by the antigen-antibody reaction which acts on the cell-walls, histamine is released and thereafter produces the allergic symptoms. This classically simple interpretation of the allergic process was renewed lately in a more complicated and theoretically preferable form. Several authors believe the allergic reaction to be the result of allergen activating the preformed reagin contained in the cells, and this as catalyser releases a great quantity of $H$. substance. These $H$. substances, of which histamine is the most important, produce the symptoms which can be observed clinically. These $H$. substances which produce the allergic symptoms are products of the irritation of the cells caused by the allergen reaction which starts those well-known changes in the small veins - namely, increase in diameter and permeability.

This short sketch of the allergic mechanism shows the need for variability in the treatment of allergic diseases. Anti-allergic treatment can be specific when we try to prevent the real cause, the meeting of allergen-reagin, by preventing access of the specific allergen to the system. In other cases we try to exclude the reagin by desensitization. This specific treatment is rather complicated, and demands special technique. Therefore simpler methods have been sought in the treatment of allergic diseases, including those of ocular origin. Such were found when the significance of the $H$. substances in the causation of allergic diseases became known, and it seemed desirable to eliminate these H. substances. Such treatment was not specific, and had formerly been tried in utilising the fermentation of histamine to alleviate allergic diseases. Long ago we used "Torantil" for this purpose. This proteid substance, derived from the mucuous membrane of the intestines, can inactivate histamine and sometimes restrains allergic manifestations. One tablet was prescribed three times daily, but it often fails in practice notwithstanding its theoretical value.

The difficulty of searching for a specific antigen and the technical obstacles to be óvercome before it can act as a desensitiser induced me some years ago to use histamine to lessen or abolish constitutional hypersensitivity. The diagnostic value of the histamine

* Received for publication March 1, 1949.

From the II Opbthalmological Clinic of the Pázmány Péter University in Budapest. Director: Professor Tibor Nonay. 
skin-test which I formerly recommended was also an aid in deciding the line of treatment. When the histamine skin-test was positive, I tried to lessen hypersensitivity in allergic eye-diseases by injecting histamine under the skin. I noted obvious and lasting results several times, and this treatment is often used by us in allergic eyediseases. It is uncertain how histamine hypodermically administered in small, increasing doses, produces a favourable result in allergic eye-diseases. Perhaps increasing doses of histamine accustom the constitution to endogenous histamine effects, such as may arise in an allergic disease. The beneficial effect of histamine introduced in increasing quantities is based not so much on the production of antibodies, as on the outpouring of adrenalin thereby provoked. Histamine can produce the formation of antibodies only in the form of complex antigen, so that presumably the good effect of histamine treatment is due to adrenalin, though histamine sub: cutaneously linked with tissue-protein plays the part of a complex antigen.

Recent researches have produced synthetic substances which can inhibit histamine. Amidst the numerous experimentally tested drugs are several so-called anti-allergic drugs used clinically with success. The basis of the knowledge is the protective effect of certain phenol-ethers against histamine intoxication. . Staub and Bovet in 1937, stated that fatal anaphylactic shock of a hypersensitised guinea-pig can be avoided by thymoxyethyldiæthylamin $929 \mathrm{~F}$, but this substance proved toxic. Further research resulted in such synthetic anti-histamines as antergan, neo-antergan, antistin, benadryl and pyri-benzamin. All of them neutralise histamine, abolish or minimise allergic manifestations and are almost non-toxic. Antergan medicinally used in France has caused death, but neoantergan is less toxic. The daily dose of each is $0.6 \mathrm{gm}$., benadryl and pyridenzamin are produced in America, and the dose of each is $50 \mathrm{mgm}$. by the mouth. Favourable results were obtained in allergic diseases such as urticaria, œdema of Quincke, hay-fever, vasomotor rhinitis and pruritus., Dean recently described a case in which fever due to penicillin treatment, dyspncea and general urticaria ceased a few hours after administering $130 \mathrm{mgm}$. of benadryl. Its accessory effects, such as fainting, palpitation and nervousness, are mild:

Rosso considers ocular manifestations in the intermenstrual period of certain women as allergic. He believes that in this period there is a surplus of histamine-like substances. These disturb the biochemical equilibrium of the aqueous humour and conduce to various eye diseases. Hence we cannot always obtain good results from hormonal treatment. On this basis Rosso tried to utilise dimethylamino-ethyl-benzylamidin-hydrochloride, the antagonist of histamine 
as an anti-histamine substance. Intermenstrual episcleritis and uveitis reacted well so did conjunctival, eye-lid and other manifestations. He administered the drug orally, intravenously in a 2.0 per cent. solution, and as drops in 0.5 per cent. solution. We have no personal experience of these drugs.

The Ciba factory kindly allowed us to test their antihistamine product antistin, and we found it effective. It is a derivative of imidazolin of the priscol-privin series. Meier and Bucher verified by animal experiments in 1946 its antagonistic action upon histamine. It is uncertain whether this action is direct desensitisation of histamine or whether it can be otherwise explained, but at any rate we can expect results from antistin treatment when organic changes in the allergic constitution have not yet developed. Its favourable effect can be observed in anaphylactic symptoms and allergic diseases, as well as in diseases caused by allergic-inflammatory factors, e.g., nephritis. This effect was also described in the Hungarian literature for internal medicine. This drug was employed in many different diseases with striking success. It can be used in tablets of $100 \mathrm{mgm}$. orally, or by intramuscular injection. The average daily dose is $300 \mathrm{mgm}$. but more can be given without provoking toxic effects. Ophthalmologists are especially interested in the solution which can be applied as drops. The watery solution contains 0.5 per cent. antistin and 0.025 per cent. privin. Privin, being an imidazolin derivative checks swelling of the mucous membrane, and by contracting the veins even more than does adrenalin, it potentiates the antistin effect. We observed the remonstrable effect of antistinprivin drops in many different allergic eye-diseases, as in the following case.

1. H. G., a 60-year-old man, complained that his right upper eye-lid swelled suddenly and became irritable though not painful. His right eye was watery. On the previous night he had eaten eggs. On the right upper eye-lid there was a typical oedema of Quincke, and on the same side allergic conjunctivitis. After half-an-haur poulticing with a tampon soaked in antistin-privin solution, together with instillation of drops, he went away cured. It was not possible to determine the aetiology. Histamine skin-test was positive.

2. Sz. K., a 35-year-old man, gave a history of eczema on the scrotum and both legs in 1942. In Spring, 1943, eczema appeared on the right ear. He was treated with his own blood-serum, autovaccination from his tonsils, Castellani solution. A week ago his right eye became inflamed, and he was elsewhere given noviform ointment and targesin solution to use at home. On examination his right eye-lids were greatly swollen by involvement in the moist eczema. The inflamed conjunctiva showed increased sensitivity, as corroborated by the presence of eosinophil cells in the conjunctival sac. The histamine skin-test was strongly positive. After three days of treatment with antistin instillation and antistin tablets three times daily by mouth, the skin of the pale eye-lids peeled in scales, the conjunctiva whitened, and secretion ceased. Those who have treated such eye-diseases know, that, with ordinary therapeutic measures, resolution takes 8-10 days.

3. R. H., male, 65 years, had been treated as an out-patient for, 11 months for subacute allergic conjunctivitis. It was not possible to discover the origin of the malady but he said it developed after beavy sweating from strenous physical work. In spring he usually had a cold. The blood picture was normal, and the histaminetest positive. Before the administration of antistin he had been unsuccessfully 
treated with various drugs. His discomfort ceased after a week's instillation with antistin once daily. In 10 days he completely recovered, and there have been no relapses in the past six months.

4. Cs. L., a 40 year-old woman, had been treated for similar trouble in her right eye at an insurance hospital for six months. Various drops and milk-injections afforded no benefit. She stated that she was cured by penicillin ointment in another hospital, but three months after her recovery fresh inflammation arose in her right eye. She showed marked photophobia, and there were 8-10 superficial punctate infiltrations scattered over the cornea. This superficial keratitis, of which the cause was obscure, was probably a form of bypersensitivity, and it cleared after instillation of antistin once daily for three days. The histamine skin-test was strongly positive in this case also.

We have observed rapid benefit from antistin treatment in cases of blepharitis due to penicillin hypersensitivity, and in conjunctival diseases. The prolonged use of sulphonamides and antibiotics can sensitize the organism. Allergic symptoms arising from such causes are favourably influenced by antistin.

The same benefit ensued in a man with conjunctivitis accompanying widespread dermatitis provoked by a mercury skin ointment applied once only. Antistin instilled once daily for 3-4 days relieved him of his eye-symptoms, and also abolished eye-symptoms due to-sensitization by pilocarpin.

We also observed beneficial results in the conjunctivits of hay fever. The patient rapidly lost his discomfort. Success was also obtained in spring-catarrh treated with antistin, orally or in drops. Symptoms ceased or were relieved, though the objective picture scarcely changed.

Györffy and Kahán tried antistin in patients complaining of irritation from the wearing of contact-glasses. They supposed that over sensitiveness to the contact-glass, irritating the cornea, produced in some people an increase of histamine. More than half of these patients could wear the contact glass for a longer time after previous instillation of antistin, than they could without antistin.

Subsequently we saw favourable results in the oedema of Quincke, acute and subacute conjunctivitis accompanied by allergic dermatitis, eczema, allergic conjunctivitis including that of hay-fever, springcatarrh and superficial keratitis. Antistin given orally checked the reactions of hypersensitivity caused by penicillin,

Finally, we must mention episcleritis, iridocyclitis and uveitis of focal origin. It is supposed that noxious foci produce antigens, which cause allergic outbursts, e.g., iridocyclitis, by sensitizing the constitution. The ideal solution would be to stop the production of antigen by removal of the focus. Belated removal of the focus does not, however, always prove beneficial owing to an increase of parallergy. This explains frequent relapses even after removal of the focus. In such cases peroral treatment by antistin seems theoretically sound, but success in a few cases does not permit farreaching assumptions, and further investigations are required. Bourquin relates similar observations. With this same object we used the $5497 / 3 \mathrm{nr}$. anti-allergicum produced by the Hoftmann-la Roche factory. This drug is available in America under the name 
of Tephorin. We used it successfully for cases of chronic uveitis, in which moderate increase of monocytes denoted hypersensitivity. Good results were also obtained in some cases of spring-catarrh, though one patient complained of insomnia. He was taking 3-6 tablets a day.

In conclusion we can assert that the discovery of synthetic antihistamine substances offer a new method of treatment for allergic diseases. Such treatment is at once palliative and symptomatic. These histaminolytic substances are beneficial in ocular disease, and our results with antistin encourage us to advise these substances for trial.

\section{Summary}

The mechanism of allergy and various forms of allergic treatment are reviewed. Specific treatment is not always possible. The knowledge of $H$. substances opens up new methods of treatment. The notion of rendering substances such as histamime ineffective has, been under consideration. One may try to accustom the constitution to histamine or to desensitise the organism thereto. For diagnostic purposes in eye diseases, I advise the histamine skin-test, and note the good results obtained in allergic eye diseases by small subcutaneous injections of histamine. The latest anti-histamine drugs can inhibit histamine, and combat allergic eye diseases. Experience with antistin produced by Ciba are reviewed. Good results were seen in the oedema of Quincke, acute and subacute conjunctivitis associated with allergic dermatitis, eczema, allergic conjunctivitis, hay-fever, spring-catarrh and superficial keratitis. Antistin favourably influenced the hypersensitivity reactions caused by penicillin. In all these conditions it was applied locally, but in the treatment of episcleritis and uveitis of focal origin antistin given by the mouth often proved beneficial. In view of the good results obtained these antihistamine substances can be recommended for trial by ophthalmologists.

\section{LITERATURE}

1. Bourguin (1947)-Excerpta Med. Ophthal., 1, 442.

2. BRACK, (1947).-Schweiz. med. Wöchenschr., 76, 316.

3. CorRado (1947) -Exccrpta. Med Ophthal., 1, 637.

4. Dean (1948).-Excerpta. Med. Opkthal., 2, 160.

5. Fredenhagen (1947).-Schweiz, Rf. Med., 36, 288.

6. GREINER (1948). -Orvosok Lap., 4, 647.

7. GYÖRFFY and KAHÁN (1948).-Ibid., 1337.

8. HAJôs and RAJKA (1944).-Asthma, eczema az allergica tanának tükrében.

9. MEIER És BUCHER (1946).-Schweiz. med. Wöchenschr., 76, 294.

10. NÉMETH (1943) -Allergías szembetegségek.

11. - RA JKA (1947). - Börgyögy ês venerologiai Szemle, 1, 44.

12. Rosso (1948).-Excerpta. Med. Ophthal., 2, 692.

13. SCHINDLER (1946).-Schweiz. med. Wöchenschr., 76, 300. 